\title{
26234 - EARLY OUTCOMES OF CARDIAC SURGERY IN OCTOGENARIANS
}

\section{Linda Harris RN, Jacek Karski MD; George Djaiani, MD; Wei Xu; Ludwik Fedorko, MD PhD; Toronto General Hospital, UHN, Toronto, ONTARIO, Canada}

INTRODUCTION: The number of patients $>=80$ (octogenarians) years age presenting for cardiac surgery is increasing. Published outcome reports after cardiac surgery for octogenarians are encouraging.(1) In our institution, we have observed proportional increase in surgeries performed in this population of patients. This review was performed to assess morbidity, mortality and length of stay in the ICU and hospital of octogenarians as compared to patients in a younger population.

METHODS: After Research Ethics Board approval, we extracted data from a prospectively collected database on 189 consecutive octogenarians from January 2003 to December 2004. From the same period, we extracted data on randomly selected 600 patients 65-75 years of age. We compared preoperative, intraoperative and postoperative data between these two groups using univariant and then multivariate analysis.

Proportions were compared using Chi-square.

RESULTS: In the octogenarian group 109 (55\%) patients had primary coronary artery bypass graft (CABG) surgery, $18 \%$ only valvular surgery, $21 \%$ valve and CABG surgery, and $6 \%$ complex aortic surgery. Only $10 \%$ of patients had re-do cardiac surgery. Fifty percent of the patients were elective and the remainder was done on an urgent basis. Octogenarians were more symptomatic with respect to angina, syncope and NYHA scores. However, there were no patients with chronic renal failure or severe COPD preoperatively in the octogenarian group. The proportion of female patients was 39\% vs. $28 \%$ in octogenarian and non-octogenarian group respectively. Octogenarians had increased hospital length of stay, required more blood product transfusion, had a higher incidence of chest reopening and required more permanent pacemaker insertion. However, the ICU length of stay, mortality, stroke rate, renal failure, and infection rate was similar between the two groups. (Table I).

DISCUSSION: The results of our study showed no increase in the rate of stroke, renal failure and 30 day mortality as compared to the younger patient population. Although further studies are required it appears that age $>=80$ years is not a single contraindication to cardiac surgery.

REFERENCES

1. ANZ J Surg. 75(6):429-35, 2005 Jun 
Table I

\begin{tabular}{|l|c|c|c|}
\hline Variable & Octogenarians & Non-octogenarians & p value \\
\hline & $\mathbf{N = 1 8 9}$ & $\mathbf{N = 6 0 0}$ & \\
\hline Age (years) & $82.3 \pm 2.3$ & $70.2 \pm 3.1$ & $0.001^{*}$ \\
\hline Gender Female (\%) & 39 & 28 & 0.01 \\
\hline Angina (\%) & 48 & 36 & 0.02 \\
\hline Syncope (\%) & 12 & 4 & 0.001 \\
\hline NYHA Scores & $3 \pm 1$ & $2.7 \pm 1.2$ & $0.001^{*}$ \\
\hline Diabetes (\%) & 22 & 32 & 0.003 \\
\hline Hb preoperative & $127 \pm 15$ & $132 \pm 17$ & 0.001 \\
\hline Procedure & & & \\
\hline Aortic valve (\%) & 35 & 21.5 & 0.001 \\
\hline LITA use (\%) & 43 & 68 & 0.001 \\
\hline Chest reopening (\%) & 9.5 & 4.6 & 0.05 \\
\hline Postoperative & & & \\
\hline ICU time (hr's) & $79 \pm 109$ & $62 \pm 121$ & $\mathrm{NS}^{*}$ \\
\hline Hospital stay (days) & $11.1 \pm 10$ & $9.4 \pm 9.6$ & $0.005^{*}$ \\
\hline Pacer (\%) & 10.5 & 5.5 & 0.01 \\
\hline RBC transfusion (units) & $3.8 \pm 4.0$ & $2.5 \pm 3.2$ & $0.001^{*}$ \\
\hline Survival (30 days) (\%) & 3.2 & 1.5 & $\mathrm{NS}^{*}$ \\
\hline
\end{tabular}

"Multivariant analysis (mean SD), all other results Chi-square

Angina $=$ crescendo or acute coronary syndrome, LITA - left internal thoracic artery,

Pacer - permanent pacemaker insertion. Hb-hemoglobin level g/l 